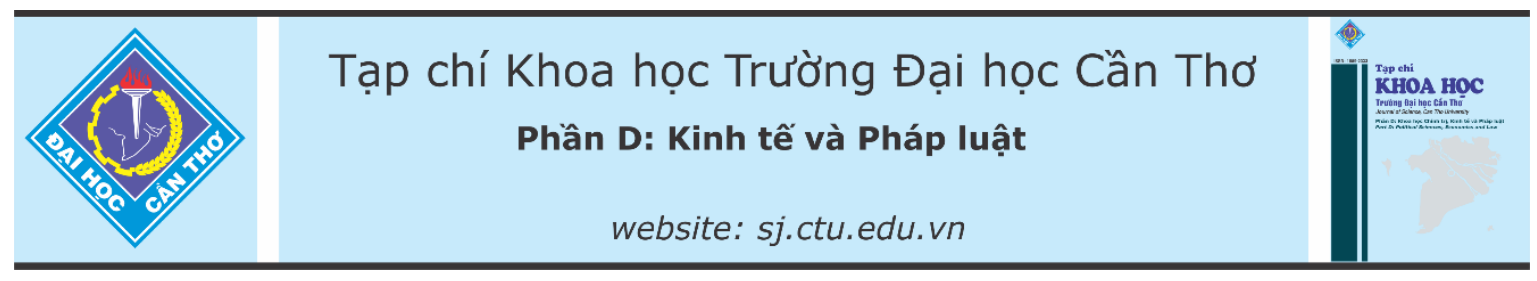

DOI:10.22144/ctu.jvn.2021.162

\title{
CÁC YẾU TỐ ẢNH HƯởNG ĐẾN Ý ĐỊNH SỬ DỤNG VÍ ĐIỆN TỬ CỦA NGƯỜI DÂN TẠI THÀNH PHỐ CẦN THOO: ÚNG DỤNG MÔ HÌNH CẤU TRÚC TUYẾN TÍNH PLS-SEM
}

\author{
Bùi Nhất Vương*
}

Khoa Vận tải Hàng không, Học viện Hàng không Việt Nam

*Nguoòi chịu trách nhiệm về bài viết: Bùi Nhất Vuoong (email: nhatvuongal @ gmail.com)

\section{Thông tin chung:}

Ngày nhận bài: 30/03/2021

Ngày nhận bài sủa: 19/06/2021

Ngày duyệt đăng: 29/10/2021

Title:

Factors Influencing

Consumer's Intention to Use E-

wallets in Can Tho City:

Application of Partial Least

Squares Structural Equation

Modeling (PLS-SEM)

\section{Tù khóa:}

PLS-SEM, TP. Cần Tho, ý định sủ dụng ví điện tử

\section{Keywords:}

Can Tho City, intention to use e-wallets, PLS-SEM

\section{ABSTRACT}

The aim of this research is to discover factors that affect the intention to use e-wallets through the mediating roles of attitude toward using $e$ wallets. Survey data collected from 201 respondents who have knowledge of e-wallet as Momo, Zalopay, AirPay, ViettelPay in Can Tho city was analyzed to provide evidence. Results from the partial least squares structural equation modeling (PLS-SEM) indicated that perceived credibility, facilitating conditions, performance expectancy, and social influence positively affects the intention to use e-wallets. Based on the results, a new approach was proposed to predicting the intention to use e-wallets through the mediating role of attitude toward using the $e$-wallet. Specifically, performance expectancy and social influence only indirectly impacted intention to use e-wallets; perceived credibility had a direct and indirect influence on users' intention, and facilitating conditions only directly affected intention to use e-wallets. Finally, some recommendations were proposed to enhance the intention to use the ewallet of customers in Can Tho City.

\section{TÓM TẮT}

Mục tiêu của nghiên cứu này là khám phá ra nhũng yếu tố ảnh hưởng đến $\dot{y}$ định sư dụng ví điện tử thông qua vai trò trung gian của thái độ đối với sư dụng sản phẩm. Dũ liệu được thu thập là 201 đáp viên có hiểu biết về ví điện tử Momo, ZaloPay, AirPay, ViettelPay tại thành phố Cần Tho, đã được phân tích để cung cấp bằng chứng. Kết quả tù̀ mô hình phương trình cấu trúc bình phuoong nhỏ nhất một phần (PLS-SEM) chỉ ra rằng nhận thức uy tín, diều kiện thuận lợ, hiệu quả kỳ vọng và ảnh hưởng xã hội có ảnh hương tích cưc đến ý định sử dụng ví điện tử. Bên cạnh đó, nghiên cưu này đã đề xuất cách tiếp cânn mới để dụ đoán biến ý định sử dụng ví điện tử thông qua vai trò trung gian của thái độ của khách hàng để dụ đoán ý định sư dụng ví điện tủ của nguời tiêu dùng. Cu thể, biến hiệu quả mong đợi và ảnh hương xã hội chỉ tác động gián tiếp đến ý định sư dụng vi điện tử; nhận thức uy tín đã tác động trực tiếp và gián tiếp đến ý định sử dụng ví điện tử, và điều kiện thuận lợi chi tác động trục tiếp đến ý định sư dụng ví điện tử. Cuối cùng, nghiên cúu cũng đã đề xuất một số hàm ý quản trị để nâng cao ý định sư dụng ví điện tử của người dân tại thành phố Cần Tho: 


\section{GIỚI THIẸU}

Trong bối cảnh đại dịch COVID-19, thế giới đang trải qua một trong những cuộc suy thoái trầm trọng nhất kể từ cuộc đại chiến thế giới thứ hai (Minds, 2021). Trao đổi truyền thống đã phải giảm bớt do các nguyên nhân như hạn chế gặp mặt nhau trong giờ giới nghiêm (Guthrie, 2021). Bên cạnh đó, COVID-19 đã thúc đẩy việc chuyển đổi trao đổi vật lý sang thương mại điện tử (Hassan et al., 2020). Trong thập kỷ vừa qua, sự phát triển của thương mại điện tử đã dẫn đến sự bùng nổ của các hình thức thanh toán điện tử. Thanh toán điện tử được định nghĩa là một nền tảng được dùng để thanh toán hàng hóa/dịch vụ thông qua internet, là sự chuyển tiền từ tài khoản này sang tài khoản khác. Trong đó, ví điện tử là một loại công nghệ cao hơn trong lĩnh vực tài chính (Wulantika \& Zein, 2020).

Tiền giấy tưởng chừng như không thể thay thế giờ đây đang đối mặt với nguy cơ bị thay thế bởi tiền điện tử và sự xuất hiện của ví điện tử đã tạo nên một sự ảnh hưởng khổng lồ đến các dịch vụ tài chính (Bansal, 2020). Ví điện tử có thể thực hiện thanh toán mà chẳng cần đến tiền mặt hay các loại tài sản tương đương tiền. Do đó, ví điện tử đóng một vai trò quan trọng trong thương mại ngày nay, nó thay thế cho tiền mặt và ví vật lý dưới dạng số, nó lưu trữ các thông tin cá nhân như thẻ thanh toán trên thiết bị di động bởi các lợi ích mà nó mang lại như tiện lợi, chi phí thấp, giao dịch nhanh chóng, an toàn... (Kolandaisamy \& Subaramaniam, 2020). Ví điện tử có thể được hiểu như một công nghệ trả trước trực tuyến được dùng để giữ tiền và giao dịch trực tuyến thông qua điện thoại thông minh hoặc giao dịch kỹ thuật số (Rathore, 2016). Trong tình hình đại dịch căng thẳng đang diễn ra, việc ứng dụng giao dịch từ xa để hạn chế tiếp xúc trực tiếp là cần thiết. Vì vậy, những lợi ích của ví điện tử đã thúc đẩy người dân sử dụng nó ngày càng phổ biến.

Theo thống kê của Công ty Công nghệ giải trí Việt Nam năm 2018, Việt Nam có $72 \%$ dân số sở hữu điện thoại thông minh, $68 \%$ sử dụng điện thoại thông minh để truy cập internet (nhiều hơn máy tính). Tỷ lệ người tiêu dùng thanh toán bằng di động ở Việt Nam tăng từ mức $37 \%$ vào năm 2018 lên mức $61 \%$ năm 2019 và đây cũng là mức tăng cao nhất trong số 6 quốc gia Đông Nam Á tham gia khảo sát (Nguyễn Thị Ánh Ngọc và ctv., 2020). Ngoài ra, kênh thanh toán qua điện thoại di động tăng trưởng $124-125 \%$ cả về số lượng và giá trị. Tính đến cuối năm 2020, Việt Nam có khoảng 130 công ty trong lĩnh vực công nghệ tài chính, tăng gấp 3 lần về số lượng của năm 2017. Trong đó, thanh toán vẫn là phân khúc lớn nhất, chiếm $31 \%$ tổng số lượng khởi nghiệp về công nghệ tài chính (Baodautu, 2021).

Ví điện tử là một trong những hình thức thanh toán điện tử phổ biến hiện nay bên cạnh các dịch vụ như internet banking, thanh toán bằng thẻ,... Nhờ vào tính tiện lợi của nó, đại dịch xảy ra đã đóng vai trò như một đòn bẩy giúp thị trường ví điện tử tăng trưởng vượt bậc trong thời gian này. Theo Ngân hàng Nhà nước Việt Nam, hiện tại có 39 ví điện tử đang hoạt động trong nước (Vnexpress, 2020). Trong đó, năm ví lớn nhất (Momo, Samsung Pay, bankplus, PayPal, Zalo Pay) chiếm tới $95 \%$ tổng số giao dịch (Baodautu, 2021). Năm 2019, số giao dịch qua ví điện tử mỗi năm là 60 triệu lượt, giá trị bình quân mỗi giao dịch ví điện tử là 200.000 đồng, giá trị giao dịch bình quân qua mỗi ví điện tử theo ngày và tháng lần lượt là 58.870 đồng và 1.700 .000 đồng (Hà Thư, 2019).

Hiện nay, không có bất cứ nghiên cứu thực nghiệm nào về ý định (YD) sử dụng ví điện tử tại Cần Thơ. Do đó, nghiên cứu các yếu tố ảnh hưởng đến YD sử dụng ví điện tử được thực hiện nhằm giúp cho các nhà quản trị nắm bắt $\mathrm{YD}$ của khách hàng và từ $\mathrm{YD}$ dẫn đến hành vi sử dụng ví điện tử là thực sự cần thiết. Từ đó, nghiên cứu đưa ra các đề xuất nhằm nâng cao khả năng sử dụng ví điện tử, góp phần nâng cao khả năng thu hút người dùng của các công ty công nghệ tài chính trong bối cảnh thị trường ví điện tử bùng nổ như hiện nay.

\section{TỔNG QUAN NGHIÊN CÚU}

\subsection{Khái niệm về ví điện tử}

Ví điện tử được biết đến như một ví kỹ thuật số hay ví di động (Uddin \& Akhi, 2014). Khi điện thoại thông minh là một phần không thể thiếu của cuộc sống hiện nay, thì nó trở thành bàn đạp cho sự hình thành của ví kỹ thuật số và số lượng người sử dụng ví kỹ thuật số đã tăng trưởng khổng lồ (Bantwa \& Padiya, 2020). Ý tưởng về ví điện tử được hình thành trong những năm về trước, khi người ta chuyển đổi tiền giấy sang thẻ ghi nợ và thẻ tín dụng như một cách bảo mật thanh toán dựa trên hình thức thanh toán bằng thẻ thông minh với các thành viên của sáu tổ chức gồm American Express, Discover, $\mathrm{JCB}$, Mastercard, Union Pay và Visa (Alaeddin et al., 2018). Các nước như Mỹ, Nhật, Thụy Điển và Hàn Quốc đã trình bày những giải pháp ví kỹ thuật số dựa trên điện thoại di động cho người tiêu dùng sử dụng điện thoại của họ để chi trả cho tạp hóa, đặt đồ uống từ một máy bán hàng tự động và đặt vé máy bay (Rathore, 2016). 
Sharma et al. (2018) cho rằng ví điện tử là cách thức mới nhất của thương mại di động cho phép người dùng thực hiện giao dịch, mua sắm trực tuyến, đặt hàng và chia sẻ những dịch vụ sẵn có. Ví điện tử là một chương trình hoặc một dịch vụ web cho phép người dùng lưu trữ và kiểm soát thông tin mua hàng trực tuyến của họ như thông tin đăng nhập, mật khẩu, địa chỉ giao hàng và chi tiết thẻ tín dụng.

Nghị định 80/2016/NĐ-CP định nghĩa dịch vụ ví điện tử là dịch vụ cung cấp cho khách hàng một tài khoản điện tử định danh do các tổ chức cung ứng dịch vụ trung gian thanh toán tạo lập trên vật mang tin (như chip điện tử, sim điện thoại di động, máy tính...), cho phép lưu giữ một giá trị tiền tệ được đảm bảo bằng giá trị tiền gửi tương đương với số tiền được chuyển từ tài khoản thanh toán của khách hàng tại ngân hàng vào tài khoản đảm bảo thanh toán của tổ chức cung ứng dịch vụ ví điện tử theo tỷ lệ $1: 1$ (Chinhphu, 2016).

Ví điện tử còn là một hình thức của ngân hàng trực tuyến khi nó thực hiện một số nhiệm vụ như chi trả cho hàng hóa hay dịch vụ trực tiếp từ tài khoản ngân hàng, chuyển tiền, cung cấp séc điện tử, tiền điện tử, đặt hàng thanh toán điện tử... Nói cách khác, những dịch vụ của ngân hàng đều được thực hiện bởi ví điện tử (Uddin \& Akhi, 2014).

\subsection{Khái niệm về YD sử dụng dịch vụ}

Ajzen (1988) cho rằng YD hành vi là khả năng chủ quan của con người dự định đạt được trong một thời gian nhất định. Theo Tirtiroglu và Elbeck (2008), YD sử dụng là miêu tả sự sẵn lòng của khách hàng để sử dụng một sản phẩm nào đó. Hay Zhao và Othman (2010) định nghĩa YD là một quá trình hành động mà một cá nhân muốn đạt được. Ajzen et al. (1975) cho rằng $\mathrm{YD}$ hành vi là sự đo lường $\mathrm{YD}$ của một cá thể để thực hiện một hành vi cụ thể hay YD hành vi là những cảm giác tích cực hay tiêu cực đối với việc thực hiện một hành vi mục tiêu. YD hành vi sử dụng là khuynh hướng một cá nhân thể hiện, nó chỉ ra rằng liệu họ sử dụng một công nghệ mới hay không. Một người sẽ thể hiện hành vi nếu như họ có YD đó (Latupeirissa et al., 2020). Mức độ sử dụng công nghệ có thể được dự đoán từ hành vi tham gia vào công nghệ (Davis, 1989). Kết quả nghiên cứu của Peña-García et al. (2020) chỉ ra rằng $\mathrm{YD}$ hành vi sẽ có ảnh hưởng tích cực đến việc sử dụng công nghệ. Nghiên cứu này giả định rằng $\mathrm{YD}$ hành vi sẽ có ảnh hưởng tích cực đến sử dụng ví điện tử trong tương lai.

\subsection{Mô hình nghiên cứu}

Mô hình lý thuyết về hợp nhất chấp nhận và sử dụng công nghệ (UTAUT) được Venkatesh et al. (2003) đề xuất là sự kết hợp giữa các yếu tố từ các mô hình khác nhau. Cụ thể là, hiệu quả kỳ vọng (HQKV) được kết hợp từ cảm nhận sự hữu ích, động lực bên ngoài, công việc thích hợp, lợi thế tương đối và kết quả kỳ vọng. Nỗ lực kỳ vọng (NLKV) là sự kết hợp của cảm nhận dễ sử dụng tính phức tạp, tính dễ sử dụng. Ảnh hưởng xã hội (AHXH) được hình thành từ chuẩn chủ quan, yếu tố xã hội, hình ảnh. Điều kiện thuận lợi (ĐKTL) bao gồm cảm nhận kiểm soát hành vi, ĐKTL, tính tương thích. Theo Venkatesh et al. (2003), nhân tố thái độ (TĐ) đối với sản phẩm là nhân tố mạnh nhất ảnh hưởng đến YD hành vi trong một số trường hợp như: mô hình lý thuyết hành động hợp lý (TRA), mô hình lý thuyết hành vi dự định (TPB). Ngoài ra, mô hình UTAUT lại thiếu đi nhân tố liên quan đến bảo mật, rủi ro hay uy tín. Do đó, dựa vào các mô hình lý thuyết, các nghiên cứu trước liên quan (Peña-García et al., 2020; Wijaya et al., 2020) và kết quả thảo luận nhóm, nghiên cứu này đã được đề xuất các nhân tố ảnh hưởng đến YD sử dụng ví điện tử gồm: $\mathrm{HQKV}$, NLKV, AHXH, ĐKTL, TD đối với sản phẩm và nhận thức uy tín (NTUT) (Hình 1). 


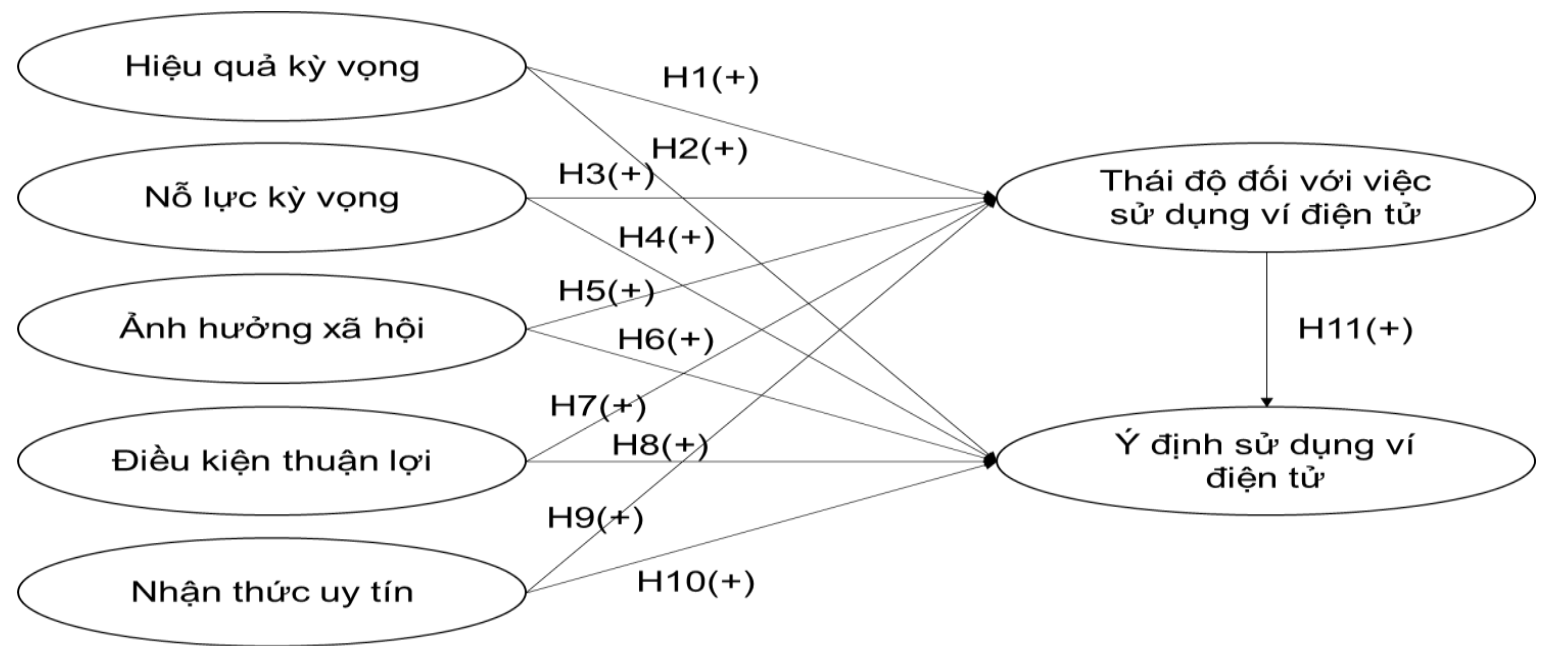

Hình 1. Mô hình và giả thuyết nghiên cứu được đề xuất

\subsubsection{Hiệu quả kỳ vọng (HQKV)}

Venkatesh et al. (2003) định nghĩa HQKV là "mức độ một cá nhân tin rằng sử dụng hệ thống sẽ giúp anh ây/cô ấy đạt được hiệu quả trong công việc". Ví điện tử cung cấp cho người dùng đa dạng các loại hình giao dịch giúp cho người dùng có được sự tiện lợi nhiều hơn so với việc đi trực tiếp lại quầy và chờ đợi thanh toán. Ngoài ra, người dùng còn được những lợi ích khác như chuyển tiền không mất phí, chiết khấu giá khi nạp tiền/mua thẻ điện thoại, các thẻ giảm giá khi mua hàng của các thương hiệu khác nhau giúp cho người dùng tiết kiệm được chi phí. Việc ứng dụng ưu điểm của ví điện tử là nhanh chóng, tiện lợi đã giúp cho người dùng có khả năng hoàn thành công việc của họ mà không phải sử dụng nhiều nỗ lực. Với khả năng lưu trữ các giao dịch, người dùng có thể dễ dàng quản lý các giao dịch của họ và cân bằng chi tiêu. Nghiên cứu dự đoán rằng nếu người dùng có thể nhận thấy những lợi ích mà ví điện tử đem lại, nó sẽ giúp cho người dùng có $\mathrm{TD}$ tích cực đối với sử dụng ví điện tử. Nghiên cứu còn giả định rằng khi ví điện tử gia tăng lợi ích mà người dùng nhận được khi sử dụng thì nó làm cho người dùng có nhiều YD sử dụng ví điện tử hơn. Bên cạnh đó, một số nghiên cứu trước (Giao et al., 2020; Widyanto et al., 2020) đã chứng minh rằng $\mathrm{HQKV}$ có ảnh hưởng tích cực đến TD sử dụng và $\mathrm{YD}$ sử dụng. Vì vậy, các giả thuyết được đề xuất như sau:

Giả thuyết $\mathrm{H}_{1}$ : $\mathrm{HQKV}$ có ảnh hưởng tích cực đến TD đối với việc sử dụng ví điện tử.

Giả thuyết $\mathrm{H}_{2}: \mathrm{HQKV}$ có ảnh hưởng tích cực đến YD sử dụng ví điện tử.

\subsubsection{Nỗ lục kỳ vọng (NLKV)}

NLKV là mức độ dễ dàng khi sử dụng một hệ thống (Venkatesh et al., 2003). Khi một người chưa sử dụng hệ thống và bắt đầu học cách sử dụng hệ thống thì NLKV là mức độ mà họ có thể dễ dàng học cách sử dụng hệ thống này. Sau khi biết được cách sử dụng, họ có thể dễ dàng ghi nhớ được cách để sử dụng hệ thống này và trở nên thành thạo trong việc sử dụng hệ thống. Một khía cạnh khác, sự tương tác giữa người dùng và hệ thống có thể được hiểu một cách dễ dàng. Nghiên cứu cho rằng khi người dùng có thể dễ dàng sử dụng một hệ thống thì họ sẽ có $\mathrm{TD}$ tích cực đối với việc sử dụng hệ thống đó và gia tăng YD sử dụng hệ thống. Giao et al. (2020) cho rằng $\mathrm{NLKV}$ có ảnh hưởng tích cực đến cả $\mathrm{TD}$ sử dụng và $Y D$ sử dụng. Do đó, các giả thuyết được đề xuất như sau:

Giả thuyết $\mathrm{H}_{3}$ : NLKV có ảnh hưởng tích cực đến TD đối với sử dụng ví điện tử.

Giả thuyết $\mathrm{H}_{4}$ : NLKV có ảnh hưởng tích cực đến YD sử dụng ví điện tử.

\subsubsection{Anh hưởng xã hội (AHXH)}

Theo mô hình lý thuyết về UTAUT, AHXH là mức độ một cá nhân cảm nhận những người quan trọng với họ cho rằng họ nền sử dụng hệ thống (Venkatesh et al. 2003). Những nhân tố có khả năng ảnh hưởng đến sự chấp nhận công nghệ của người tiêu dùng bao gồm thành viển trong gia đình, bạn bè, đồng nghiệp và hàng xóm (Sarika \& Vasantha, 2019). Bagozzi and Dholakia (2002) đề cập thêm ngoài những đối tượng đó, môi trường và cộng đồng trực tuyến tạo thuận lợi cho TD tích cực của người dùng đối với sản phẩm. Chaouali et al. (2016) báo cáo $\mathrm{AHXH}$ ảnh hưởng đến cách tư duy của mỗi cá 
nhân trong việc sử dụng một sản phẩm đổi mới thông qua dịch vụ công nghệ. Các nghiên cứu khác (Jiwasiddi et al., 2019; Yang et al., 2021) cho rằng $\mathrm{AHXH}$ có ảnh hưởng đến $\mathrm{TD}$ sử dụng và $\mathrm{YD}$ sử dụng. Nghiên cứu giả định $\mathrm{AHXH}$ có ảnh hưởng tích cực đến $\mathrm{TD}$ đối với sử dụng ví điện tử và $\mathrm{YD}$ sử dụng ví điện tử. Các giả thuyết được đề xuất như sau:

Giả thuyết $\mathrm{H}_{5}$ : $\mathrm{AHXH}$ có ảnh hưởng tích cực đến TD đối với sử dụng ví điện tử.

Giả thuyết $\mathrm{H}_{6}$ : $\mathrm{AHXH}$ có ảnh hưởng tích cực đến $\mathrm{TD}$ đối với sử dụng ví điện tử.

\subsection{4. Điều kiện thuận lợi (ĐKTL)}

ĐKTL là mức độ một cá nhân tin rằng cơ sở hạ tầng về kỹ thuật và tổ chức hỗ trợ họ sử dụng công nghệ (Venkatesh et al., 2003). Giao et al. (2020) còn cho rằng ĐKTL là tính khả dụng của các nguồn tài nguyên như các loại tài liệu hay cơ sở hạ tầng công nghệ có thể hỗ trợ trong việc sử dụng công nghệ mới. Chawla and Joshi (2020) lại bổ sung việc huấn luyện cách sử dụng công nghệ hoặc tính tương thích của công nghệ vào định nghĩa ĐKTL. Mahran and Enaba (2013) và Giao et al. (2020) cho rằng ĐKTL có ảnh hưởng đến cả $\mathrm{TD}$ sử dụng và $\mathrm{YD}$ sử dụng. Hossain et al. (2017) chứng minh rằng ĐKTL có mối quan hệ tích cực đến YD sử dụng sản phẩm của người tiêu dùng. Yang et $\mathrm{al}$. (2021) cho rằng $\mathrm{ĐKTL}$ có ảnh hưởng đến YD sử dụng ví điện tử. Nghiên cứu cho rằng $\mathrm{OKTL}$ có ảnh hưởng tích cực đến $\mathrm{TD}$ và YD sử dụng ví điện tử. Do đó, các giả thuyết được đề xuất như sau:

Giả thuyết $\mathrm{H}_{7}$ : ĐKTL có ảnh hưởng tích cực đến TD đối với việc sử dụng ví điện tử.

Giả thuyết $\mathrm{H}_{8}$ : ĐKTL có ảnh hưởng tích cực đến YD sử dụng ví điện tử.

\subsubsection{Nhận thức uy tín (NTUT)}

Vuong et al. (2020) cho rằng NTUT là mức độ một cá nhân tin rằng sử dụng hệ thống công nghệ bởi tính đáng tin cậy và bảo mật. Một hệ thống công nghệ càng đáng tin cậy và bảo mật thì người dùng sẽ càng yên tâm để sử dụng hệ thống đó. Ngoài ra, NTUT còn thể hiện ở việc cung cấp cho người dùng những cách bảo mật đáng tin cậy tránh bị xâm nhập. Bên cạnh đó là các hình thức hỗ trợ người dùng có thể lấy lại tài khoản trong trường hợp bị xâm nhập. Nếu người dùng có thể cảm thấy an tâm về việc bảo mật và có những cách xử lý nếu tài khoản bị lấy cắp, thì họ sẽ có $\mathrm{TD}$ tích cực hơn với việc sử dụng hệ thống cũng như YD sử dụng hệ thống đó. Giao et al. (2020) cho rằng nNTUT có ảnh hưởng tích cực đến
TD sử dụng và YD sử dụng. Vuong et al. (2020) đã kết luận rằng NTUT có ảnh hưởng đến TD sử dụng và $\mathrm{YD}$ của người dùng đối với việc sử dụng công nghệ. Vì vậy, các giả thuyết được đề xuất như sau:

Giả thuyết $\mathrm{H}_{9}$ : NTUT có ảnh hưởng tích cực đến TD đối với việc sử dụng ví điện tử.

Giả thuyết $\mathrm{H}_{10}$ : NTUT có ảnh hưởng tích cực đối với YD sử dụng ví điện tử.

\subsubsection{TD đối với sử dụng ví điện tử}

TD có thể được định nghĩa như sau "cảm nhận tích cực hay tiêu cực của một cá nhân về việc thực hiện hành vi mục tiêu" (Davis, 1989, p.335) . Yang et al. (2021) cho rằng TD đối với sử dụng sản phẩm là cảm giác vui sướng, phấn khởi, hài lòng/không hài lòng, thất vọng hay sự chán ghét bởi một cá nhân với một hành động cụ thể. Mahran and Enaba (2013) khẳng định $\mathrm{TD}$ đối với sản phẩm có tác động trực tiếp đến $Y D$ hành vi và $Y D$ hành vi được cấu thành bởi TD của một người. Giao et al. (2020) cho rằng TD đối với sử dụng sản phẩm công nghệ có ảnh hưởng đến YD sử dụng công nghệ. Do đó, giả thuyết được đề xuất như sau:

Giả thuyết $\mathrm{H}_{11}$ : $\mathrm{TD}$ đối với sử dụng ví điện tử có ảnh hưởng tích cực đến YD sử dụng ví điện tử.

\subsubsection{Vai trò trung gian của TD đối với sử dụng ví điện tử}

Ảnh hưởng trung gian gợi ý rằng tác động của biến độc lập đến biến phụ thuộc không xảy ra một cách trực tiếp mà ảnh hưởng được chuyển qua một nhân tố thứ ba được gọi là một biến trung gian (mediating variable). Nói cách khác, ảnh hưởng trung gian đại diện cho mối quan hệ "gián tiếp" giữa các hiện tượng. Cụ thể, nhân tố thứ ba tiếp nối ảnh hưởng từ hiện tượng này đến hiện tượng khác phục vụ như thể nó là một trung gian giữa hai bên (Hà Nam Khánh Giao và Bùi Nhất Vương, 2019). Trong marketing, một nhân tố chính tác động đến YD sử dụng dịch vụ của người dùng là $\mathrm{HQKV}$ của dịch vụ đó (Venkatesh et al., 2003). HQKV liên quan đến sự phỏng đoán của người dùng về sử dụng dịch vụ ví điện tử sẽ giúp anh ây/cô ây đạt được hiệu quả trong công việc (Venkatesh et al., 2003). Tuy nhiên, liệu rằng $\mathrm{HQKV}$ là lý do đủ mạnh tác động đến $\mathrm{YD}$ khách hàng sử dụng dịch vụ? Nó có tác động trực tiếp đến YD của khách hàng? Trước khi người dùng có YD sử dụng dịch vụ ví điện tử bởi vì hiệu quả nó mang lại trong công việc, thì những người dùng có thể cần có TD tích cực với dịch vụ trước. TD tích cực đối với sản phẩm/dịch vụ là quan trọng, vì nếu khách hàng nghĩ hiệu quả của một sản phẩm là tốt, nhưng họ không có cảm nhận tích cực với nó, thì 
khách hàng sẽ không muốn mua sản phẩm, dù cho thế nào đi nữa. Trong nghiên cứu marketing, TD đối với sản phẩm/dịch vụ đã và đang được tìm thấy như một nhân tố chính khác thúc đẩy người tiêu dùng mua hàng (Giao et al., 2020; Widyanto et al., 2020). Trong trường hợp này, ảnh hưởng của $\mathrm{HQKV}$ có thể không tác động trực tiếp YD mua hàng, nhưng có thể được chuyển gián tiếp qua vai trò của TD đối với sản phẩm/dịch vụ. Nói một cách đơn giản, HQKV dẫn đến TD tích cực đối với sản phẩm/dịch vụ; TD tích cực đối với sản phẩm/dịch vụ dẫn đến YD mua. TD tích cực đối với sản phẩm/dịch vụ trong trường hợp này là biến trung gian liên kết mối quan hệ giữa HQKV và YD sử dụng dịch vụ.

Tương tự, theo mô hình lý thuyết về UTAUT, khi những người dùng trải nghiệm thú vị, dễ chịu, HQKV, uy tín, $A H X H$ tích cực liên quan đến việc sản phẩm thì họ có xu hướng thể hiện $\mathrm{TD}$ tích cực đến sản phẩm và từ đó, họ sẽ tăng YD sử dụng sản phẩm. Do đó, rất có thể TD đối với sản phẩm đóng vai trò là biến trung gian cho các mối quan hệ này. Nói cách khác, các biến HQKV, NLKV, AHXH, NTUT, ĐKTL tác động gián tiếp đến YD sử dụng sản phẩm thông qua biến $\mathrm{TD}$ đối với sử dụng sản phẩm. Các nghiên cứu trước cũng đã xác nhận vai trò trung gian của TD đối với sử dụng giữa những biến này và $\mathrm{YD}$ sử dụng sản phẩm công nghệ (Giao et al., 2020; Kim et al., 2018; Venkatesh et al., 2003). Vì vậy, các giả thuyết sau được đề xuất:

Giả thuyết $\mathrm{H}_{12 a}$ : HQKV tác động gián tiếp đến YD sử dụng ví điện tử thông qua biến trung gian TD đối với sử dụng ví điện tử.

Giả thuyết $\mathrm{H}_{12 \mathrm{~b}}$ : NLKV tác động gián tiếp đến YD sử dụng ví điện tử thông qua biến trung gian TD đối với sử dụng ví điện tử.

Giả thuyết $\mathrm{H}_{12 c}$ : $\mathrm{AHXH}$ tác động gián tiếp đến YD sử dụng ví điện tử thông qua biến trung gian TD đối với sử dụng ví điện tử.

Giả thuyết $\mathrm{H}_{12 \mathrm{~d}}$ : ĐKTL tác động gián tiếp đến YD sử dụng ví điện tử thông qua biến trung gian TD đối với sử dụng ví điện tử.

Giả thuyết $\mathrm{H}_{12 \mathrm{e}}$ : NTUT tác động gián tiếp đến YD sử dụng ví điện tử thông qua biến trung gian TD đối với sử dụng ví điện tử.

\section{PHUUƠNG PHÁP NGHIÊN CÚU}

\subsection{Phương pháp thu thập số liệu}

Sau khi thực hiện lược khảo tài liệu nhằm xây dựng mô hình nghiên cứu giả thuyết và thang đo sơ bộ. Thang đo được hình thành bởi các biến quan sát từ các nghiên cứu trước ở nước ngoài. Vì vậy, thang đo được dịch từ tiếng Anh sang tiếng Việt và sau đó được dịch ngược để đảm bảo độ chính xác của thang đo (Hà Nam Khánh Giao và Bùi Nhất Vương, 2019).

Trước khi thực hiện khảo sát chính thức, nghiên cứu sơ bộ bằng phương pháp thảo luận tay đôi với cỡ mẫu là 10 người có hiểu biết về ví điện tử (Momo, ZaloPay, AirPay, ViettelPay) tại thành phố Cần Thơ (TP.Cân Thơ) nhằm đảm bảo sự phù hợp của mô hình cũng như của thang đo so với thực tế và điều chỉnh sao cho mọi người đều có thể nắm bắt hiểu rõ.

Sau khi thực hiện thảo luận tay đôi, nghiên cứu thu được kết quả như sau: với đề cương thảo luận được đưa ra hầu hết những người tham gia đều đồng ý rẳng: nội dung thảo luận dễ hiểu, rõ ràng. Các gợi ý đưa ra để đo lường các thang đo hầu như khá đầy đủ. Bên cạnh đó, kết quả cho thấy không có yếu tố nào mới được đề xuất ngoài 06 yếu tố đã được đề xuất. Vì vậy, thang đo chính thức đã phù hợp và có thể được sử dụng vào khảo sát chính thức.

Hair et al. (2009) đề xuất rằng nếu mô hình có số cấu trúc có biến tiềm ẩn ít hơn hoặc bằng 7 và mỗi cấu trúc nhiều hơn ba câu hỏi thì cỡ mẫu tối thiểu cần thiết là 150 . Bollen (1989) cũng gợi ý rằng kích thước mẫu tối thiểu phải gấp 5 lần số biến quan sát. Thang đo nghiên cứu gồm 33 biến quan sát vì vậy kích cỡ mẫu bằng với $33 * 5=165$. Hà Nam Khánh Giao và Bùi Nhất Vương (2019) cho rằng cỡ mẫu từ 100 đến 200 là đủ tốt để thực hiện phân tích mô hình PLS-SEM. Vì vậy, nghiên cứu chọn cỡ mẫu $\mathrm{N}=$ 200, phù hợp với đề xuất của Hair et al. (2009), Bollen (1989), và Hà Nam Khánh Giao và Bùi Nhất Vương (2019). Hơn nữa, để đảm bảo số lượng cỡ mẫu thu về là 200 , Hà Nam Khánh Giao và Bùi Nhất Vương (2019) cũng đã đề xuất rằng số lượng phiếu khảo sát phát ra nên tăng thêm $15 \%$ cỡ mẫu tối tiểu vì trong quá trình thu thập dữ liệu sẽ phải loại bỏ những bảng khảo sát không đạt yêu cầu. Vậy số phiếu được gửi đi khảo sát là: $200 *(1+15 \%)=230$.

Nghiên cứu này được thực hiện tại TP. Cần Thơ với phương pháp chọn mẫu thuận tiện. Đối tượng khảo sát là những người dân đang sinh sống tại TP. Cần Thơ có hiểu biết về ví điện tử (Momo, ZaloPay, AirPay, ViettelPay). Dữ liệu được thu thập bằng phương pháp phỏng vấn trực tiếp và Google biểu mẫu trực tuyến. Bảng câu hỏi gồm 04 phần: (1) phần giới thiệu, (2) phần sàng lọc, (3) phần nội dung khảo sát và (4) phần thông tin cá nhân. Đối với phần 
sàng lọc, nghiên cứu đã đưa ra câu hỏi như sau: "Xin vui lòng cho biết, Anh/Chị có hiểu biết về một trong các loại ví điện tủ Momo, ZaloPay, AirPay, và ViettelPay hay không?" Nếu đáp viên trả lời "Có" thì tiếp tục khảo sát, ngược lại thì ngừng khảo sát.

\subsection{Phương pháp ước lượng}

Nghiên cứu này sử dụng mô hình phương trình cấu trúc bình phương nhỏ nhất một phần (PLSSEM) để kiểm tra giả thuyết. Hà Nam Khánh Giao và Bùi Nhất Vương (2019) cho rằng PLS có thể đóng góp nhiều tiện ích cho phân tích hành vi trong nghiên cứu hành vi. Ngoài ra, PLS cũng được công nhận về khả năng hoạt động tốt với các kích thước mầu nhỏ (100-200), những nghiên cứu có ít lý thuyết có nền, và dữ liệu không cần phân phối chuẩn
(Hà Nam Khánh Giao \& Bùi Nhất Vương, 2019). Bằng cách xem xét tất cả các điểm mạnh ở trên, phần mềm SmartPLS 3.0 đã được sử dụng để để phân tích dữ liệu trong nghiên cứu này.

\section{KÊT QUẢ NGHIÊN CÚU}

Sau khi thực hiện khảo sát, nghiên cứu thu thập được 225 quan sát. Trong đó, 201 người có hiểu biêt về ví điện tử (Momo, ZaloPay, AirPay, ViettelPay) và 24 người không hiểu biết về ví điện tử nhưng vẫn trả lời bảng hỏi thông qua Google biểu mẫu trực tuyến, 24 người này được loại bỏ ra khỏi kết quả thu thập nhằm làm sạch dữ liệu và tiến hành mã hóa dữ liệu cho các yếu tố nhân khẩu học (Bảng 1).

Bảng 1. Đặc điểm đối tượng khảo sát

\begin{tabular}{|c|c|c|c|}
\hline & $\mathrm{N}=201$ & Tần số & Tỷ lệ (\%) \\
\hline \multirow{2}{*}{ Giới tính } & Nữ & 108 & 53,7 \\
\hline & Nam & 93 & 46,3 \\
\hline \multirow{4}{*}{ Độ tuổi } & Dưới 22 tuổi & 95 & 47,3 \\
\hline & 22-35 tuổi & 101 & 50,2 \\
\hline & 36-45 tuồi & 3 & 1,5 \\
\hline & Trên 45 tuổi & 2 & 1,0 \\
\hline \multirow{4}{*}{ Trình độ học vấn } & Trung học phổ thông & 6 & 3,0 \\
\hline & Cao đẳng/trung cấp & 10 & 5,0 \\
\hline & Đại học & 168 & 83,6 \\
\hline & Sau đại học & 17 & 8,5 \\
\hline \multirow{6}{*}{ Nghề nghiệp } & Sinh viên & 143 & 71,1 \\
\hline & Công nhân & 4 & 2,0 \\
\hline & Nông dân & 1 & 0,5 \\
\hline & Công chức - viên chức & 10 & 5,0 \\
\hline & Nhân viên văn phòng & 24 & 11,9 \\
\hline & Kinh doanh & 19 & 9,5 \\
\hline \multirow{5}{*}{ Thu nhập } & Dưới 5 triệu VND & 130 & 64,7 \\
\hline & 5-10 triệu VND & 45 & 22,4 \\
\hline & 10-15 triệu VND & 19 & 9,5 \\
\hline & Trên 15 triệu VND & 7 & 3,5 \\
\hline & Tổng cộng & 201 & 100 \\
\hline
\end{tabular}

\section{1. Đánh giá độ tin cậy của cấu trúc}

Mặc dù các nghiên cứu có thể sử dụng hệ số Cronbach's Alpha hoặc độ tin cậy tổng hợp $(\mathrm{CR})$ dể kiểm định độ tin cậy của thang đo. Tuy nhiên, Hà Nam Khánh Giao và Bùi Nhất Vương (2019) cho rằng hệ số Cronbach's Alpha có thể đánh giá vượt quá hoặc đánh giá thấp độ tin cậy của thang đo. Bênh cạnh đó, họ cũng cho rằng độ tin cậy tổng hợp phù hợp với mô hình PLS hơn Cronbach's Alpha. Chỉ số độ tin cậy tổng hợp có giá trị từ 0 đến 1 và 1 là mức độ hoàn hảo. Đối với mô hình nghiên cứu khám phá, độ tin cậy tổng hợp phải $\geq 0,6$ (Vuong \& Giao, 2020). Độ tin cậy tổng hợp của HQKV là 0,954 , NLKV là 0,883 , AHXH là 0,943 , DKTL là 0,840, NTUT là 0,959 , TD đối với sử dụng ví điện tử là 0,949 và YD sử dụng ví điện tử là 0,949 . 


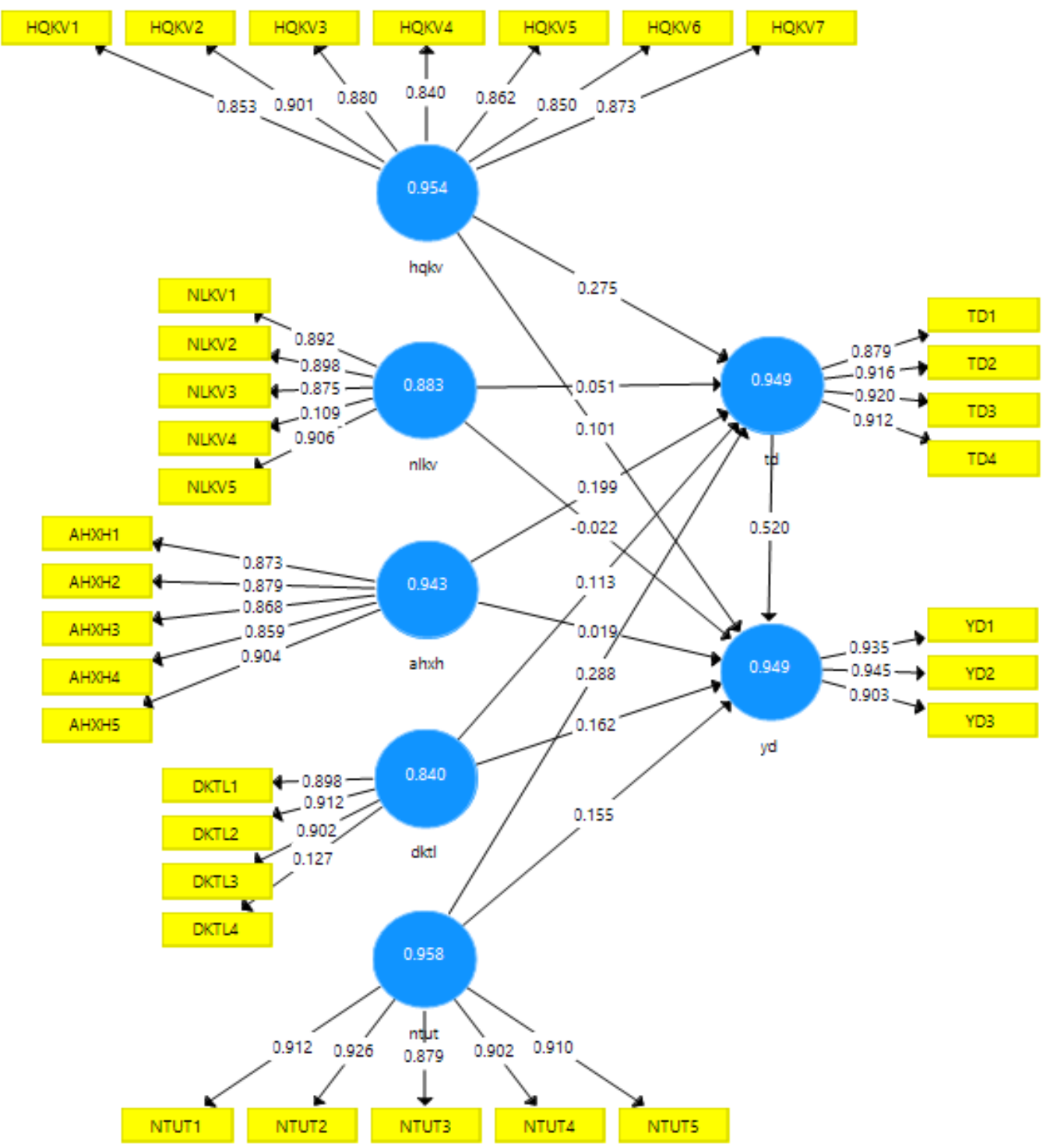

Hình 2. Độ tin cậy của mô hình

Trong hình 2 , hệ số tải của các biến quan sát đều lớn hơn 0,8 ngoại trừ 2 biến quan sát là NLKV4 (Anh/Chị cảm thấy khó khăn để ghi nhớ cách sủ dụng ví điện tư) có hệ số tải 0,109 và DKTL4 (Vi điện tư không tuoong thích với nhũng điện thoailiúng dụng Anh/Chị đang sủ dụng) có hệ số tải là 0,127 . Vì hai biến quan sát này có hệ số tải quá thấp làm giảm độ tin cậy của thang đo, nên hai biến quan sát này đã bị loại bỏ ra khỏi thang đo. Sau khi thực hiện loại biến quan sát, độ tin cậy tổng hợp của cấu trúc NLKV và $\mathrm{DKTL}$ đã tăng lên. Cụ thể là, $\mathrm{HQKV}$ là 0,954, NLKV là $0,941, \mathrm{AHXH}$ là 0,943 , ĐKTL là 0,932 , NTUT là 0,958 , TD đối với sử dụng ví điện tử và YD sử dụng ví điện tử là 0,949 (Bảng 2). Hệ số tải của các biến quan sát trong thang đều lớn hơn 0,8 và không có biến quan sát nào có hệ số tải là thiếu tin cậy. Do đó, thang đo có độ tin cậy nhất quán bên trong tốt (internal consistency reliability). 
Bảng 2. Hệ số tải các thang đo và độ tin cậy tổng họ̣p của các cấu trúc sau bước loại biến quan sát

\begin{tabular}{|c|c|c|c|c|}
\hline Cấu trúc & Thang đo & $\begin{array}{c}\text { Hệ số } \\
\text { tải }\end{array}$ & $\begin{array}{c}\text { Độ tin cậy } \\
\text { tô̂ng hợp } \\
\text { (CR) }\end{array}$ & $\mathbf{R}^{2}$ \\
\hline \multirow{7}{*}{ HQKV } & $\begin{array}{l}\text { Sử dụng ví điện tử giúp Anh/Chị thực hiện các giao dịch nhanh } \\
\text { hơn }\end{array}$ & 0,853 & \multirow{7}{*}{0,954} & \\
\hline & $\begin{array}{l}\text { Sử dụng ví điện tử giúp Anh/Chị thực hiện các giao dịch dễ } \\
\text { dàng hơn }\end{array}$ & 0,901 & & \\
\hline & Anh/Chị nhận thấy rằng sử dụng ví điện tử là hữu ích & 0,880 & & \\
\hline & $\begin{array}{l}\text { Sử dụng ví điện tử giúp Anh/Chị quản lý các giao dịch của } \\
\text { mình một cách hiệu quả hơn }\end{array}$ & 0,840 & & \\
\hline & $\begin{array}{l}\text { Giao dịch qua ví điện tử hữu ích hơn những cách giao dịch } \\
\text { truyền thống }\end{array}$ & 0,862 & & \\
\hline & \multirow{2}{*}{$\begin{array}{l}\text { Giao dịch qua ví điện tử tốn nhiều thời gian giao dịch }(\mathrm{R}) \\
\text { Sử dụng ví điện tử giúp Anh/Chị tiết kiệm được chi phí giao } \\
\text { dịch }\end{array}$} & 0,850 & & \\
\hline & & 0,873 & & \\
\hline \multirow{4}{*}{ NLKV } & Anh/Chị có thể dễ dàng sử dụng ví điện tử & 0,893 & \multirow{4}{*}{0,941} & \\
\hline & Anh/Chị có thể dễ dàng học cách sử dụng ví điện tử & 0,898 & & \\
\hline & Anh/Chị có thể dễ dàng thành thạo cách sử dụng ví điện tử & 0,877 & & \\
\hline & Các tương tác của Anh/Chị với hệ thống là rõ ràng và dễ hiểu & 0,905 & & \\
\hline \multirow{5}{*}{ AHXH } & $\begin{array}{l}\text { Những người ảnh hưởng đến hành vi của Anh/Chị nghĩ rằng } \\
\text { Anh/Chị nên sử dụng ví điện tử }\end{array}$ & 0,873 & \multirow{5}{*}{0,943} & \\
\hline & $\begin{array}{l}\text { Những người quan trọng với Anh/Chị nghĩ rằng Anh/Chị nên } \\
\text { sử dụng ví điện tử }\end{array}$ & 0,879 & & \\
\hline & Những người bạn của Anh/Chị sử dụng ví điện tử & 0,868 & & \\
\hline & \multirow{2}{*}{$\begin{array}{l}\text { Những người trong gia đình Anh/Chị sử dụng ví điện tử } \\
\text { Ví điện tử được sử dụng rộng rãi trong những cộng đồng mà } \\
\text { Anh/Chị tham gia }\end{array}$} & 0,859 & & \\
\hline & & 0,904 & & \\
\hline \multirow{3}{*}{ ĐKTL } & \multirow{3}{*}{$\begin{array}{l}\text { Anh/Chị có điện thoại thông minh để sử dụng ví điện tử } \\
\text { Anh/Chị có đủ kiến thức để sử dụng ví điện tự } \\
\text { Anh/Chị được cung cấp những trợ giúp và hỗ trợ để sử dụng ví } \\
\text { điện tữ }\end{array}$} & 0,905 & \multirow{3}{*}{0,932} & \\
\hline & & 0,913 & & \\
\hline & & 0,900 & & \\
\hline \multirow{5}{*}{ NTUT } & $\begin{array}{l}\text { Anh/Chị tin vào khả năng của ví điện tử trong việc bảo vệ } \\
\text { những thông tin cá nhân và quyền riêng tư của Anh/Chị }\end{array}$ & 0,912 & \multirow{5}{*}{0,958} & \\
\hline & $\begin{array}{l}\text { Anh/Chị tin rằng những giao dịch của Anh/Chị được thực hiện } \\
\text { qua ví điện tử là bảo mật }\end{array}$ & 0,926 & & \\
\hline & $\begin{array}{l}\text { Anh/Chị tin rằng ví điện tử sẽ trợ giúp Anh/Chị trong bất kỳ } \\
\text { trường hợp nào }\end{array}$ & 0,879 & & \\
\hline & $\begin{array}{l}\text { Ví điện tử có các hình thức bảo mật tiên tiến tránh bị xâm nhập } \\
\text { tài khoản }\end{array}$ & 0,902 & & \\
\hline & $\begin{array}{l}\text { Ví điện tử cung cấp nhiều hình thức lấy lại tài khoản trong } \\
\text { trường hợp tài khoản bị mất cắp }\end{array}$ & 0,910 & & \\
\hline \multirow{4}{*}{$\begin{array}{l}\text { TD đối với } \\
\text { sử dụng ví } \\
\text { điện tử }\end{array}$} & Sử dụng ví điện tử là một ý kiến tốt & 0,879 & \multirow{4}{*}{0,949} & \multirow{4}{*}{0,720} \\
\hline & Sử dụng ví điện tử là một quyết định sáng suốt & 0,916 & & \\
\hline & Anh/Chị thích thú khi sử dụng ví điện tử & 0,920 & & \\
\hline & $\begin{array}{l}\text { Anh/Chị tin rằng sử dụng ví điện tử là phù hợp với xu hướng } \\
\text { hiện nay }\end{array}$ & 0,912 & & \\
\hline \multirow{3}{*}{$\begin{array}{l}\text { YD sử } \\
\text { dụng }\end{array}$} & Anh/Chị có YD sử dụng ví điện tử trong tương lai & 0,935 & \multirow{3}{*}{0,949} & \multirow{3}{*}{0,746} \\
\hline & Anh/Chị sẽ sử dụng ví điện tử trong tương lai & 0,945 & & \\
\hline & Anh/Chị có kế hoạch sử dụng ví điện tử trong tương lai & 0,903 & & \\
\hline
\end{tabular}

Ghi chú: (R): câu hỏi đảo ngược để kiểm tra mức độ tập trung của đáp viên.

Ghi chú: (R): câu hỏi đảo ngược để kiểm tra mức độ tập trung của đáp viên. 


\section{2. Đánh giá tính giá trị hội tụ của thang đo}

Phương sai trích trung bình (AVE) có thể được sử dụng như một chỉ số kiểm định về tính giá trị hội tụ (convergent validity) và giá trị phân biệt của thang đo (discriminant validity). AVE phản ảnh phương sai trung bình cho mỗi cấu trúc tiềm ẩn trong mô hình nghiên cứu. Thang đo đạt giá trị hội tụ khi AVE $>0,5$ (Vuong \& Giao, 2020). AVE < 0,5 có nghĩa là phương sai sai số vượt quá phương sai được giải thích (Hà Nam Khánh Giao \& Bùi Nhất Vương, 2019). Phương sai trích trung bình của các cấu trúc được trình bày ở Bảng 3 . HQKV $=0,749$, $\mathrm{NLKV}=0,798, \mathrm{AHXH}=0,769$, ĐKTL $=0,821$, NTUT $=0,821$, TD đối với sử dụng ví điện tử $=$ 0,823 và $Y D$ sử dụng ví điện tử là 0,861 . Tất cả các cấu trúc đều có $\mathrm{AVE}>0,5$, do đó thang đo có giá trị hội tụ tốt.

Mặt khác, thang đo đạt giá trị phân biệt khi căn bậc hai của AVE lớn hơn so với phương sai của bất kỳ biến tiềm ẩn nào khác (Hà Nam Khánh Giao \& Bùi Nhất Vương, 2019). Trong bảng tiêu chuẩn Fornell-Larcker, căn bậc hai của AVE ở trong các ô đường chéo và mối tương quan giữa các biển xuất hiện bên dưới nó. Do đó, giá trị tuyệt đối của căn bậc hai của AVE lớn hơn bất kỳ hệ số tương quan nào trong cột và hàng chứa nó thì thang đo đó có giá trị phân biệt (Giao et al., 2020). Bảng FornellLarcker (Bảng 3) cho kết quả các giá trị căn bậc hai của AVE. Các giá trị này đều lớn hơn các giá trị cùng hàng và cùng cột. Do đó, mô hình đã đạt được giá trị phân biệt tốt.

Bảng 3. Bảng giá trị phân biệt Fornell-Larcker (Fornell-Larcker criterion)

\begin{tabular}{lrrrrrrrr}
\hline & AVE & AHXH & DKTL & HQKV & NLKV & NTUT & TD & YD \\
\hline AHXH & 0,769 & $\mathbf{0 , 8 7 7}$ & & & & & & \\
DKTL & 0,821 & 0,684 & $\mathbf{0 , 9 0 6}$ & & & & & \\
HQKV & 0,749 & 0,775 & 0,822 & $\mathbf{0 , 8 6 6}$ & & & & \\
NLKV & 0,798 & 0,732 & 0,795 & 0,858 & $\mathbf{0 , 8 9 3}$ & & & \\
NTUT & 0,821 & 0,804 & 0,692 & 0,808 & 0,763 & $\mathbf{0 , 9 0 6}$ & & $\mathbf{0 , 9 0 7}$ \\
TD & 0,823 & 0,760 & 0,719 & 0,801 & 0,746 & 0,789 & \\
YD & 0,861 & 0,713 & 0,721 & 0,772 & 0,713 & 0,758 & 0,837 & $\mathbf{0 , 9 2 8}$ \\
\hline
\end{tabular}

\section{3. Đánh giá vấn đề đa cộng tuyến}

Bảng 4 cho kết quả các giá trị hệ số phương sai phóng đại (VIF) của thang đo. Các biến quan sát đều mang hệ số phương sai phóng đại (VIF) đều nhỏ hơn 5. Do đó, có thể kết luận giữa các biến quan sát không xảy ra hiện tượng đa cộng tuyến.
Bảng 4. Bảng giá trị VIF của các cấu trúc

\begin{tabular}{lcc}
\hline Biến & TD & YD \\
\hline AHXH & 3,305 & 3,447 \\
DKTL & 3,391 & 3,444 \\
HQKV & 4,205 & 4,475 \\
NLKV & 4,629 & 4,636 \\
NTUT & 3,807 & 4,103 \\
TD & & 3,569 \\
\hline
\end{tabular}

Theo kết quả kiểm định giả thuyết ở Hình 3 và Bảng 5 , kết quả của các giả thuyết và mối liên hệ trong mô hình được diễn giải như sau. 


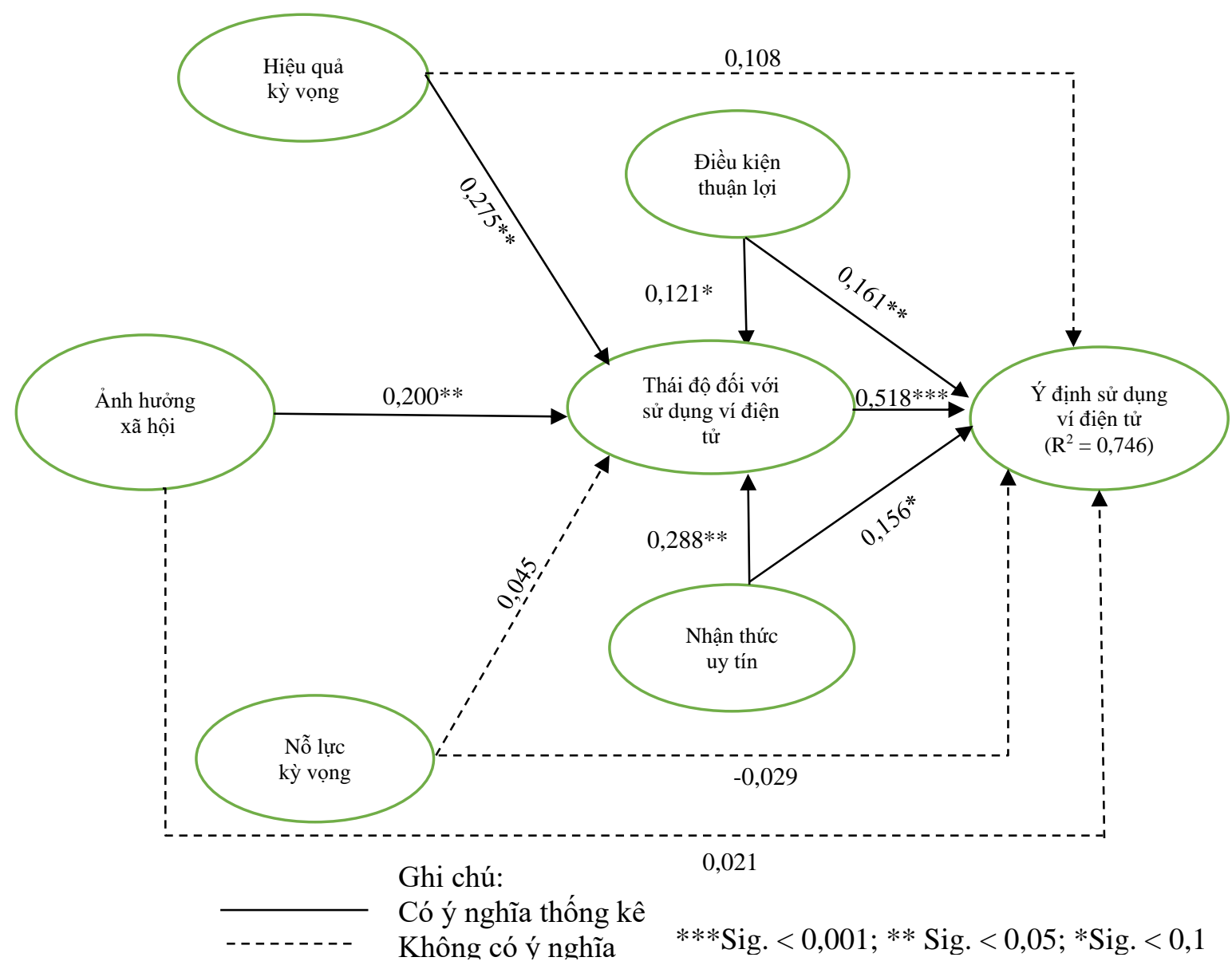

\section{Hình 3. Mô hình cấu trúc tuyến tính}

Thứ nhất, kết quả phân tích đã cho thấy rằng HQKV, AHXH, NTUT đã có ảnh hưởng tích cực đối với $\mathrm{TD}$ sử dụng ví điện tử $\left(\beta_{1,7,9}>0\right.$ và giá trị $\left.\mathrm{P}_{1,7,9}<0,05\right)$ tại mức ý nghĩa $5 \%$. Bên cạnh đó, ĐKTL có ảnh hưởng đối với TD sử dụng ví điện tử $\left(\beta_{5}>0\right.$ và giá trị $\left.\mathrm{P}_{5}<0,1\right)$ tại mức ý nghĩa $10 \%$. Do đó, giả thuyết $\mathrm{H}_{1}, \mathrm{H}_{5}, \mathrm{H}_{7}, \mathrm{H}_{9}$ được chấp nhận. Tuy nhiên, NLKV đã không có ảnh hưởng đến TD sử dụng ví điện tử với giá trị $\mathrm{P}_{3}$ là 0,649 . Vì vậy, giả thuyết $\mathrm{H}_{3}$ đã bị bác bỏ.

Bảng 5. Bảng kết quả của mối quan hệ giữa các cấu trúc trong mô hình

\begin{tabular}{ccccrc}
\hline Giả thuyết & & Mối quan hệ & & Hệ số hồi quy & Giá trị P Kết quả \\
\hline $\mathrm{H}_{1}$ & HQKV & $\rightarrow$ & TD & 0,275 & 0,006 Ủng hộ \\
$\mathrm{H}_{2}$ & HQKV & $\rightarrow$ & YD & 0,108 & 0,310 Không ủng hội \\
$\mathrm{H}_{3}$ & NLKV & $\rightarrow$ & TD & 0,045 & 0,649 Không ủng hộ \\
$\mathrm{H}_{4}$ & NLKV & $\rightarrow$ & YD & $-0,029$ & 0,745 Không ủng hộ \\
$\mathrm{H}_{5}$ & $\mathrm{AHXH}$ & $\rightarrow$ & TD & 0,200 & 0,007 Ung hộ \\
$\mathrm{H}_{6}$ & $\mathrm{AHXH}$ & $\rightarrow$ & YD & 0,021 & 0,808 Không ủng hộ \\
$\mathrm{H}_{7}$ & $\mathrm{DKTL}$ & $\rightarrow$ & TD & 0,121 & 0,098 Ung hộ \\
$\mathrm{H}_{8}$ & $\mathrm{DKTL}$ & $\rightarrow$ & YD & 0,161 & 0,026 Unng hộ \\
$\mathrm{H}_{9}$ & NTUT & $\rightarrow$ & TD & 0,288 & 0,001 Unng hộ \\
$\mathrm{H}_{10}$ & NTUT & $\rightarrow$ & YD & 0,156 & 0,078 Unng hộ \\
$\mathrm{H}_{11}$ & TD & $\rightarrow$ & YD & 0,518 & 0,000 Unng hộ \\
\hline
\end{tabular}


Thứ hai, kết quả nghiên cứu cũng đã thể hiện rằng $\mathrm{OKTL}$, và $\mathrm{TD}$ sử dụng ví điện tử đã có tác động cùng chiều đến YD sử dụng ví điện tử $\left(\beta_{8,11}>0\right.$ và giá trị $\left.\mathrm{P}_{8,11}<0,05\right)$ tại mức ý nghĩa $5 \%$. Thêm vào đó, NTUT có ảnh hưởng tích cực đến YD sử dụng ví điện tử $\left(\beta_{10}>0\right.$ và giá trị $\left.\mathrm{P}_{10}<0,1\right)$ tại mức ý nghĩa $10 \%$. Do đó, giả thuyết $\mathrm{H}_{8}, \mathrm{H}_{10}, \mathrm{H}_{11}$ đã được chấp nhận. Ngược lại, HQKV, NLKV, và $\mathrm{AHXH}$ đã không có ảnh hưởng đến YD sử dụng ví điện tử (giá trị $\left.\mathrm{P}_{2,4,6}>0,05\right)$. Vì thế, giả thuyết $\mathrm{H}_{2}, \mathrm{H}_{4}, \mathrm{H}_{6}$ đã bị bác bỏ.

\subsection{Vai trò trung gian của biến TD đối với sử dụng ví điện tử}

Ngoài ra, kết quả chứng minh vai trò trung gian của biến TD sử dụng ví điện tử giữa các biến khác và biến phụ thuộc $\mathrm{YD}$ sử dụng ví điện tử được trình bày như sau.
Giả thuyết $\mathrm{H}_{11}$ đã chứng minh rằng $\mathrm{TD}$ sử dụng ví điện tử có ảnh hưởng trực tiếp tích cực đối với YD sử dụng ví điện tử. Do đó, để chứng minh được vai trò biến trung gian của TD sử dụng ví điện tử cần phải chứng minh được các ảnh hưởng trực tiếp của các yếu tố khác đến TD sử dụng ví điện tử.

Theo kết quả của các mối quan hệ đã được diễn giải bên trên, nghiên cứu chứng minh bốn giả thuyết $\mathrm{H}_{1}, \mathrm{H}_{5}, \mathrm{H}_{7}$ và $\mathrm{H}_{9}$ lần lượt là $\mathrm{HQKV}$ có ảnh hưởng tích cực đến TD sử dụng ví điện tử, $\mathrm{AHXH}$ có ảnh hưởng tích cực đến TD sử dụng ví điện tử, NTUT có ảnh hưởng tích cực đến TD sử dụng ví điện tử và ĐKTL có ảnh hưởng tích cực đến TD sử dụng ví điện tử.

Nghiên cứu thực hiện kiểm định vai trò trung gian của yếu tố TD sử dụng ví điện tử và cho kết quả trình bày ở Bảng 6 nhằm đưa ra các kết luận theo thực nghiệm.

Bảng 6. Bảng kết quả vai trò trung gian của biến TD đối với sử dụng ví điện tử

\begin{tabular}{lrllrr}
\hline Mối quan hệ & Trực tiếp & Gián tiếp $\begin{array}{l}\text { Loại ảnh hưởng } \\
\text { trung gian }\end{array}$ & Kết quả & $\begin{array}{r}\text { Tổng ảnh } \\
\text { hưởng }\end{array}$ & $\begin{array}{r}\text { Xếp } \\
\text { hạng }\end{array}$ \\
\hline HQKV $\rightarrow$ TD $\rightarrow$ YD & 0,108 & $0,142^{* *}$ Trung gian toàn phần & Chấp nhận & $0,142^{* *}$ & 3 \\
NTUT $\rightarrow$ TD $\rightarrow$ YD & $0,156^{*}$ & $0,149^{* *}$ Trung gian bán phần & Chấp nhận & $0,305^{* *}$ & 1 \\
AHXH $\rightarrow$ TD $\rightarrow$ YD & 0,021 & $0,104^{* *}$ Trung gian toàn phần & Chấp nhận & $0,104^{* *}$ & 4 \\
DKTL $\rightarrow$ TD $\rightarrow$ YD & $0,161^{* *}$ & 0,063 & Từ chối & $0,161^{* *}$ & 2 \\
NLKV $\rightarrow$ TD $\rightarrow$ YD & $-0,029$ & 0,023 & Từ chối & - & - \\
\hline
\end{tabular}

TD sử dụng ví điện tử có vai trò trung gian trong mối quan hệ giữa $\mathrm{HQKV}$ và YD sử dụng ví điện tử với hệ số hồi quy là 0,142 và giá trị $\mathrm{P}$ là 0,009 . Do đó, vai trò trung gian này được hỗ trợ về mặt thống kê. Ngoài ra, HQKV không có ảnh hưởng tích cực trực tiếp đến YD sử dụng ví điện tử theo giả thuyết $\mathrm{H}_{2}$. Vì vậy, $\mathrm{TD}$ sử dụng ví điện tử giữ vai trò trung gian toàn phần giữa hai biến này. Do đó, giả thuyết $\mathrm{H}_{12 \mathrm{a}}$ đã được chấp nhận. Kết quả này cho thấy rằng, HQKV đã ảnh hưởng đến YD sử dụng ví điện tử chỉ qua cơ chế gián tiếp, và tổng ảnh hưởng của nó là 0,142 . Với mức ảnh hưởng này, $\mathrm{HQKV}$ đã được xếp mạnh thứ ba trong bốn nhân tố ảnh hưởng đến YD sử dụng ví điện tử của người dân tại TP. Cần Thơ.

Ảnh hưởng gián tiếp của $\mathrm{NLKV} \rightarrow \mathrm{TD} \rightarrow \mathrm{YD}$ cũng không có ý nghĩa thống kê (giá trị $\mathrm{P}>0,05$ ). Do đó, TD sử dụng ví điện tử không đóng vai trò trung gian giữa biến này và $\mathrm{YD}$ sử dụng ví điện tử. Vì vậy, giả thuyết $\mathrm{H}_{12 b}$ bị bác bỏ. Bên cạnh đó, NLKV cũng không có ảnh hưởng trực tiếp đến TD sử dụng ví điện tử theo giả thuyết $\mathrm{H}_{3}$. Từ đó, nghiên cứu đã chỉ ra rằng NLKV hoàn toàn không ảnh hưởng đến YD sử dụng ví điện tử của người dân tại TP. Cần Thơ.
TD sử dụng ví điện tử có vai trò trung gian trong mối quan hệ giữa $\mathrm{AHXH}$ và $\mathrm{YD}$ sử dụng ví điện tử với hệ số hồi quy là 0,104 và $\mathrm{P}$-value là 0,012 . Do đó, vai trò trung gian này được hỗ trợ về mặt thống kê. Ngoài ra, AHXH không có ảnh hưởng trực tiếp đến YD sử dụng ví điện tử theo giả thuyết $\mathrm{H}_{6}$. Vì vậy, TD sử dụng ví điện tử giữ vai trò trung gian toàn phần giữa hai biến này. Do đó, giả thuyết $\mathrm{H}_{12 \mathrm{c}}$ đã được chấp nhận. Kết quả này cho thấy rằng, $\mathrm{AHXH}$ đã ảnh hưởng đến YD sử dụng ví điện tử chỉ qua cơ chế gián tiếp, và tổng ảnh hưởng của nó là 0,104 . Với mức ảnh hưởng này, HQKV đã được xếp thứ tư trong bốn nhân tố ảnh hưởng đến YD sử dụng ví điện tử của người dân tại TP. Cần Thơ.

Ảnh hưởng gián tiếp của $\mathrm{DKTL} \rightarrow \mathrm{TD} \rightarrow \mathrm{YD}$ không có ý nghĩa thống kê với hệ số hồi quy là 0,063 và giá trị $\mathrm{P}$ là 0,111 . Do đó, vai trò trung gian này không tồn tại. Vì vậy, giả thuyết $\mathrm{H}_{12 \mathrm{~d}}$ bị bác bỏ. Do đó, trong nghiên cứu này ĐKTL chỉ tác động trực tiếp đến YD sử dụng ví điện tử với tổng mức ảnh hưởng là 0,161 . Với mức ảnh hưởng này, ĐKTL đã được xếp thứ hai trong bốn nhân tố ảnh hưởng đến YD sử dụng ví điện tử của người dân tại TP. Cần Tho. 
TD sử dụng ví điện tử có vai trò trung gian trong mối quan hệ giữa NTUT và YD sử dụng ví điện tử với hệ số hồi quy là 0,149 và $P$-value là 0,004 . Do đó, vai trò trung gian này được hỗ trợ về mặt thống kê. Vì vậy, giả thuyết $\mathrm{H}_{12 \mathrm{e}}$ được chấp nhận. Ngoài ra, NTUT có ảnh hưởng tích cực trực tiếp đến YD sử dụng ví điện tử theo giả thuyết $\mathrm{H}_{10}$. Vì vậy, $\mathrm{TD}$ sử dụng ví điện tử giữ vai trò trung gian một phần giữa hai biến này. Kết quả này cho thấy rằng NTUT đã ảnh hưởng đến YD sử dụng ví điện tử thông qua cơ chế gián tiếp và trực tiếp với tổng ảnh hưởng của nó là 0,305 . Với mức ảnh hưởng này, NTUT đã được xếp tác động mạnh nhất trong bốn nhân tố ảnh hưởng đến YD sử dụng ví điện tử của người dân tại TP. Cần Thơ.

\section{5. Đánh giá độ phù hợp của mô hình}

Theo Bảng 2, hệ số $\mathrm{R}^{2}$ của cả hai yếu tố $\mathrm{TD}$ sử dụng ví điện tử và YD sử dụng ví điện tử lần lượt là 0,720 và 0,746 đều lớn hơn 0,67 . Do đó, mô hình được giải thích mạnh.

Vì giá trị commnuality tương đương với $\mathrm{AVE}$ và giá trị $\mathrm{AVE}$ của các cấu trúc trong mô hình đều lớn hơn 0,7 (Bảng 4). Do đó, mô hình cấu trúc của nghiên cứu này đã chứng minh sự phù hợp với dữ liệu thực nghiệm.

Bảng 7. Bảng chỉ số độ phù hợp mô hình (GoF)

\begin{tabular}{lc}
\hline & GoF \\
\hline TD & 0,593 \\
YD & 0,642 \\
\hline
\end{tabular}

Giá trị GoF được trình bày trong Bảng 7 cho giá trị của hai yếu tố TD sử dụng ví điện tử là 0,593 và YD sử dụng ví điện tử là 0,642 . Vì vậy, có thể kết luận rằng mô hình PLS được xác nhận phù hợp rất tốt với dữ liệu.

\section{HÀM Ý QUẢN TRI VÀ KẾT LUẬN}

\subsection{Hàm ý quản trị}

\subsubsection{Nhận thức uy tín (NTUT)}

Kết quả nghiên cứu cho thấy NTUT là yếu tố có mức độ ảnh hưởng mạnh nhất đến YD sử dụng ví điện tử tại TP. Cần Thơ. Hiện nay, vấn nạn nhức nhối đối với thương mại điện tử cũng như thanh toán điện tử tại Việt Nam chính là thông tin bị đánh cắp, lừa đảo, gian lận tài chính và quảng cáo quấy rối người dùng. Khách hàng thường quan tâm nhiều hơn đến bảo mật của ví điện tử so với các dịch vụ thanh toán truyền thống. Do đó, các tiêu chuẩn bảo mật tốt nhất trong ngành nên được phát triển và bắt buộc đối với tất cả các nhà cung cấp dịch vụ trong nước tuân thủ. Các nhà cung cấp dịch vụ cần nâng cao tính bảo mật thông tin cá nhân và tài khoản của người dùng chính là nhiệm vụ cấp thiết của hầu hết các đơn vị cung ứng dịch vụ trực tuyến ví điện tử. Bên cạnh việc duy trì thực hiện các quy trình mã hóa và xác thực thông tin thông qua các dịch vụ an minh mạng, dịch vụ bảo mật nhằm mục đích bảo vệ thông tin của người dùng. Cụ thể là đào tạo đội ngũ nhân sự an ninh mạng chuyên nghiệp, nhanh nhạy nắm bắt tình hình an ninh mạng trong nước và thế giới, kịp thời xử lý sự cố xảy ra, đầu tư nâng cấp cơ sở hạ tầng công nghệ thông tin, phát huy hiệu quả sử dụng của các công cụ nghiệp vụ, thường xuyên kiểm tra và vô hiệu hóa các tín hiệu xâm nhập.

\subsection{2. Điều kiện thuận lợi (ĐKTL)}

Kết quả nghiên cứu cho thấy ĐKTL là yếu tố có mức độ ảnh hưởng thứ hai đến YD sử dụng ví điện tử tại TP. Cần Thơ. Để giúp khách hàng vượt qua các chướng ngại vật trong việc sử dụng ví điện tử, các nhà cung cấp dịch vụ nên cung cấp hỗ trợ người dùng bất cứ khi nào khách hàng có thắc mắc cách thức kích hoạt, các dịch vụ trả tiền qua ví điện tử... Một tập hợp các tài liệu liên quan đến việc hướng dẫn sử dụng và ứng dụng của ví điện tử cũng nên được cung cấp trên trang web chính thức của các nhà cung cấp để người dùng dễ tham khảo. Bên cạnh đó, các nhà cung cấp cũng có thể xem xét việc cung cấp các hướng dẫn miễn phí cho người dân tại các trường học, hoặc trung tâm mua sắm... Cuối cùng, các nhà cung cấp cần thiết kế phần mềm ví điện tử có thể sử dụng được trên các dòng điện thoại khác nhau, để giúp người dùng dễ dàng cài đặt khi có nhu cầu sử dụng ví điện tử.

\subsubsection{Hiệu quả kỳ vọng ( $H Q K V)$}

Kết quả nghiên cứu cho thấy HQKV là yếu tố có mức độ ảnh hưởng lớn thứ ba đến YD sử dụng ví điện tử tại TP. Cần Thơ. Các nhà cung cấp dịch vụ nên thiết kế, đổi mới bố cục giao diện ứng dụng sao cho thực sự hấp dẫn, thân thiện và dễ sử dụng đối với nhiều đối tượng khách hàng khác nhau. Ví điện tử hiện đang là xu thế thanh toán của tương lai, do đó ngày càng nhiều đối tượng khách hàng tiếp cận để sử dụng dịch vụ. Việc tiếp thu ý kiến của khách hàng một cách thường xuyên nhằm cải tiến không ngừng theo yêu cầu của khách hàng là hết sức quan trọng trong việc đánh giá cảm nhận dễ sử dụng của họ. Cải tiến quy trình, gia tăng các tính năng giúp hỗ trợ cho người dùng giảm thời gian và công sức trong việc thực hiện giao dịch bằng ví điện tử (tự động hiển thị và điền các thông tin cần thiết mà người dùng đã cung cấp vào thời điểm đăng kí sử dụng dịch vụ khi tiến hành giao dịch trên ví điện tử...) để thao tác dễ dàng hơn. 
Nghiên cứu và nắm bắt nhu cầu thanh toán ngày càng đa dạng của nhiều đối tượng khách hàng, từ đó tích hợp những tiện ích thanh toán trong nhiều lĩnh vực như dịch vụ công gồm tiền nước, tiền điện, tiền internet..., hay những chương trình trả phí định kỳ hàng tháng/năm như Netflix và Amazon... Đặc biệt, xu hướng thương mại điện tử xuyên quốc gia sẽ trở nên phổ biến trong tương lai, do đó thanh toán điện tử, đặc biệt là ví điện tử cần theo kịp và đáp ứng tốt xu hướng này.

Ngày nay, giá cả và chất lượng luôn là yếu tố mà đa số người dùng quan tâm khi tiến hành giao dịch thương mại điện tử. Vì vậy, việc liên kết chặt chẽ giữa các đơn vị cung ứng dịch vụ ví điện tử và các sàn thương mại điện tử, các website bán hàng trực tuyến là hết sức cần thiết. Ngoài những ưu đãi về giảm giá, khuyến mãi mà các sàn giao dịch thương mại điện tử hay website bán hàng trực tuyến đưa ra, các đơn vị cung ứng dịch vụ ví điện tử cũng cần chú trọng đến hoạt động gia tăng sự hấp dẫn đối với nhiều đối tượng khách hàng thông qua ưu đãi và tiện ích đi kèm, phần quà điện tử (e-gift) hấp dẫn... Bên cạnh đó, việc phối hợp, bàn bạc và hợp tác sâu rộng với các sàn giao dịch thương mại điện tử cũng như các website bán hàng trực tuyến để đưa ra những ưu đãi thực sự hấp dẫn là cần thiết nhằm kích thích người dùng thanh toán bằng dịch vụ ví điện tử. Việc bổ sung tính năng hỗ trợ người dùng trong việc lọc những mức giá "hời" là một trong những phương án giúp người dùng có cảm nhận tốt hơn về sự hữu ích của sản phẩm. Do đó, thông báo về khuyến mãi, giảm giá mới nên được gửi thông qua ứng dụng thường xuyên nhằm kích thích khách hàng sử dụng ví điện tử để thanh toán.

\subsubsection{5Ảnh hương xã hội (AHXH)}

Kết quả nghiên cứu cho thấy AHXH là yếu tố có mức độ ảnh hưởng lớn thứ tư đến YD sử dụng ví điện tử tại TP. Cần Thơ. Vì vậy, các công ty cung cấp dịch vụ ví điện tử cần phải tăng cường các hoạt động đa truyền thông hơn nữa. Đối với truyền thông xã hội, bộ phận Marketing cần tạo ra các "video story" dạng thông điệp mang tính kể chuyện dễ lan truyền chẳng hạn như "xài ví tiết kiệm" "chi tiêu cực rẻ với ví điện tử", "xài ví thả ga" bằng hình thức truyền thông đa kênh trên các mạng xã hội, Facebook, Youtube, Facebook, Zalo, Tiktok, Instagram... Trong thông điệp truyền thông phải luôn giữ được tính tiết kiệm, hiệu quả khi sử dụng ví điện tử để giúp người dùng khắc ghi vào tâm trí. Bên cạnh đó, các nhà cung cấp dịch vụ ví điện tử cũng có thể sử dụng các nhân vật nổi tiếng có uy tín để quảng bá sản phẩm và tiếp cận với các khách hàng tiềm năng với thông điệp ứng dụng ví điện tử phục vụ cho cuộc sống hàng ngày, mà còn tiết kiệm tiện lợi khi thanh toán không dùng tiền mặt.

\subsection{Kết luận}

Là một hệ thống giao dịch tài chính thay thế, ví điện tử đang nhận được sự quan tâm của người dùng trên toàn cầu. Hiện nay, chưa có nghiên cứu để khám phá YD sử dụng ví điện tử ở Cần Thơ. Để giải quyết khoảng trống nghiên cứu này, một mô hình nghiên cứu đã được phát triển để khám phá các yếu tố ảnh hưởng đến YD sử dụng ví điện tử. Nghiên cứu này vận dụng lý thuyết về mô hình UTAUT để đo lường các nhân tố ảnh hưởng đến YD sử dụng ví điện tử tại Cần Thơ.

YD sử dụng của khách hàng là một yếu tố rất quan trọng trong việc thành công của doanh nghiệp. Trong bối cảnh của nghiên cứu, YD sử dụng ví điện tử chịu tác động bởi bốn nhân tố chính sau: NTUT, ĐKTL, HQKV và $\mathrm{AHXH}$. Kết quả nghiên cứu giúp các nhà cung cấp dịch vụ ví điện tử hiểu thêm về khách hàng, hiểu những kỳ vọng của họ cũng như ý kiến đánh giá của họ về YD sử dụng ví điện tử hiện nay trên địa bàn tỉnh. Trong đó, NTUT là thành phần có ảnh hưởng mạnh nhất đến YD sử dụng ví điện tử. Vì vậy, các nhà cung cấp dịch vụ cần quan tâm thúc đẩy YD sử dụng ví điện tử, thông qua các nhân tố chính ảnh hưởng đến $\mathrm{YD}$, từ đó áp dụng những chiến lược phù hợp nhằm nâng cao sự chấp nhận ví điện tử.

Về mặt học thuật, nghiên cứu đã góp phần giới thiệu thang đo lường YD sử dụng ví điện tử trong bối cảnh nghiên cứu tại Việt Nam. YD sử dụng ví điện tử là một khái niệm không mới nhưng chưa nhận được nhiều sự quan tâm của các doanh nghiệp ở TP. Cần Thơ nói riêng, và các doanh nghiệp Việt Nam nói chung. Nghiên cứu này đã kiểm định các mô hình truyền thống trong nghiên cứu hành vi người tiêu dùng là UTAUT trong bối cảnh nghiên cứu về ví điện tử. Bên cạnh đó, nghiên cứu đề xuất cách tiếp cận mới để đo lường YD sử dụng ví điện tử thông qua vai trò trung gian của $\mathrm{TD}$ của khách hàng để dự đoán YD sử dụng ví điện tử của người tiêu dùng. Kết quả nghiên cứu cũng đã xác nhận vai trò trung gian của $T D$ đối với sử dụng ví điện tử trong mối quan hệ giữa bốn biến độc lập (NTUT, ĐKTL, HQKV, AHXH) và YD sử dụng. Nói cách khác, hầu hết các nghiên cứu trước đã chứng minh mối quan hệ trực tiếp của các biến tiền đề đến YD sử dụng sản phẩm công nghệ. Tuy nhiên, nghiên cứu này đã cung cấp bằng chứng thực nghiệm rằng, các biến tiền đề có thể ảnh hưởng gián tiếp đến YD sử dụng sản phẩm công nghệ thông qua biến trung gian 
TD đối với sử dụng ví điện tử. Cụ thể, kết quả nghiên cứu đã chỉ ra rằng biến hiệu quả mong đợi và AHXH chỉ tác động gián tiếp đến YD sử dụng ví điện tử. Nếu nghiên cứu này không xét vai trò trung gian của TD đối với sử dụng ví điện tử, thì đã loại bỏ hai biến này ra khỏi mô hình. Như vậy, chính nhờ xem xét tác động gián tiếp đã giải thích rõ ràng và đầy đủ cơ chế tác động của $H Q K V$ và $A H X H$ đến YD sử dụng. Tương tự, biến NTUT đã tác động trực tiếp và gián tiếp đến YD sử dụng ví điện tử. Cuối cùng, biến ĐKTL chỉ tác động trực tiếp đến YD sử dụng ví điện tử.

Những phát hiện này cung cấp một hướng để nhà cung cấp dịch vụ ví điện tử hiểu được các ưu tiên của người dùng. Sau khi có thông tin về các yếu tố lấy người dùng làm trung tâm, các tổ chức có thể đưa ra các chiến lược của mình cho phù hợp. Tổ chức cũng có thể định vị các dịch vụ của họ theo lựa chọn của người tiêu dùng, điều này có thể làm tăng tốc độ chấp nhận. Kết quả cũng cung cấp thông tin quan trọng cho bên thứ ba, ngân hàng và các tổ chức khác liên quan đến thanh toán điện tử. Nghiên cứu này cũng sẽ giúp chính phủ thực hiện nền kinh tế không dùng tiền mặt.

\subsection{Hạn chế và hướng nghiên cứu tiếp theo}

Mặc dù đề tài đã giải quyết xong mục tiêu nghiên cứu đã đề ra, nhưng vẫn còn một số hạn chế như sau: Thứ nhất, do hạn chế về mặt thời gian và chi phí, nghiên cứu chỉ được thực hiện thu thập dữ liệu với phương pháp lấy mẫu thuận tiện, do đó kết quả nghiên cứu chưa mang tính đại diện cao. Nghiên cứu tiếp theo nên sử dụng phương pháp lấy mẫu xác suất để tăng tính đại diện cho nghiên cứu. Hạn chế thứ hai của nghiên cứu là chỉ xem xét tác động nói chung của toàn bộ mẫu thu thập và chưa thực hiện phân tích sự khác biệt giữa đặc điểm nhân khẩu học như giới tính, thu nhập, trình độ, nghề nghiệp..., vì vậy gợi ý cho các hướng nghiên cứu tiếp theo là quan tâm đến sự khác biệt về YD sử dụng ví điện tử theo đặc điểm cá nhân của người dùng. Cuối cùng, nghiên cứu cũng chưa phân tích được sự khác biệt trong YD sử dụng ví điện tử theo nhà cung cấp. Trong nghiên cứu này, mẫu được thu thập từ những người dùng có hiểu biết về Momo, ZaloPay, AirPay, ViettelPay, nhưng rất có thể YD sử dụng mỗi ví điện tử sẽ khác nhau. Nghiên cứu tiếp theo nên thực hiện so sánh YD sử dụng bốn loại ví điện tử này.

\section{TÀI LIẸU THAM KHẢO}

Ajzen, I. (1988). Attitudes, Personality, and Behaviour. UK: McGraw-Hill Education.
Ajzen, I., Fishbein, M., \& Hill, R. J. (1975). Belief, Attitude, Intention and Behavior: An Introduction to Theory and Research. Contemporary Sociology: Addison-Wesley Publishing Company, Inc.

Alaeddin, O., Rana, A., Zaimudin, Z., \& Kamarudin, F. (2018). From physical to digital: Investigating consumer behaviour of switching to mobile wallet. Polish Journal of Management Studies, 17(2), 18-30.

Bagozzi, R. P., \& Dholakia, U. M. (2002). Intentional social action in virtual communities. Journal of Interactive Marketing, 16(2), 2-21.

Bansal, N. (2020, May 20). E-wallets and Digitization. https://www.researchgate.net/publication/3414 52663_E-wallets_and_Digitization

Bantwa, A., \& Padiya, J. (2020). Adoption of ewallets: A post demonetisation study in Ahmedabad City. Pacific Business Review International, 10(10), 84-95.

Baodautu. (2021, 01/05). Fintech bùng nổ và cuộc đua môt mất, một còn. https://baodautu.vn/fintech-bung-no-va-cuocdua-mot-mat-mot-con-d135944.html

Bollen, K. A. (1989). Structural Equations with Latent Variables. Oxford, England: John Wiley \& Sons.

Chaouali, W., Yahia, I. B., \& Souiden, N. (2016). The interplay of counter-conformity motivation, social influence, and trust in customers' intention to adopt Internet banking services: The case of an emerging country. Journal of Retailing and Consumer Services, 28(1), 209-218.

Chawla, D., \& Joshi, H. (2020). Role of Mediator in Examining the Influence of Antecedents of Mobile Wallet Adoption on Attitude and Intention. Global Business Review, 22(2), 1-17.

Chinhphu. (2016, 07/01). Nghi định 80/2016/ND-CP. http://vanban.chinhphu.vn/portal/page/portal/chin $\mathrm{hph} /$ hethongvanban?class_id=1\&_page $=1 \& \bmod$ $\mathrm{e}=$ detail\&document_id=185464.

Davis, F. D. (1989). Perceived usefulness, perceived ease of use, and user acceptance of information technology. MIS Quarterly, 13(3), 319-340.

Giao, H. N. K., Vuong, B. N., Huan, D. D., Tushar, H., \& Quan, T. N. (2020). The effect of emotional intelligence on turnover intention and the moderating role of perceived organizational support: Evidence from the 
banking industry of Vietnam. Sustainability, 12(5), 1-25.

Giao, H. N. K., Vuong, B. N., Tung, D. D., \& Quan, T. N. (2020). A model of factors influencing behavioral intention to use internet banking and the moderating role of anxiety: Evidence from Vietnam. WSEAS Transactions on Business and Economics, 17(1), 551-561.

Guthrie, C., Fosso-Wamba, S., \& Arnaud, J. B. (2021). Online consumer resilience during a pandemic: An exploratory study of ecommerce behavior before, during and after a COVID-19 lockdown. Journal of Retailing and Consumer Services, 61(7), 1-21.

Hà Nam Khánh Giao, \& Bùi Nhất Vương. (2019). Giáo Trình Cao Hoc Phuoong Pháp Nghiên Cúu Khoa Học Trong Kinh Doanh Cập Nhật SmartPLS. TP. Hồ Chí Minh, Việt Nam: Nhà Xuất Bản Tài Chính.

Hà Thư. (2019, 07/02). Tổng quan thị trường ví điện tư việt nam 2019. https://fff.com.vn/tongquan-thi-truong-vi-dien-tu-viet-nam-2019/.

Hair, J. F., Hult, G. T. M., Ringle, C. M., \& Sarstedt, M. (2017). A Primer on Partial Least Squares Structural Equation Modeling (2nd Ed.). Thousand Oaks: Sage.

Hassan, M. A., Shukur, Z., \& Hasan, M. K. (2020). An efficient secure electronic payment system for e-commerce. Computers, 9(66), 1-20.

Hossain, M. A., Hasan, M. I., Chan, C., \& Ahmed, J. U. (2017). Predicting user acceptance and continuance behaviour towards location-based services: The moderating effect of facilitating conditions on behavioural intention and actual use. Australian Journal of Information Systems, 21(6), 1-22.

Jiwasiddi, A., Adhikara, C., Adam, M., \& Triana, I. (2019). Attitude toward using fintech among Millennials. Paper presented at the Conference: Proceedings of The 1st Workshop Multimedia Education, Learning, Assessment and its Implementation in Game and Gamification, Medan Indonesia, 26th.

Kim, T. T., Karatepe, O. M., Lee, G., \& Demiral, H. (2018). Do gender and prior experience moderate the factors influencing attitude toward using social media for festival attendance? Sustainability, 10(10), 1-19.

Kolandaisamy, R., \& Subaramaniam, K. (2020). The impact of e-wallets for current generation. Journal of Advanced Research in Dynamical and Control Systems, 12(1), 751-759.
Latupeirissa, J. J. P., Subanda, I. N., \& Gorda, A. O. S. (2020). Antecedents of intention to use e-wallet: The development of acceptance model with PLS-SEM approach. Journal of Advanced Research in Dynamical and Control Systems, 12(7), 1416-1429.

Nguyễn Thị Ánh Ngọc, Đặng Thùy Linh, Nguyễn Thị Diễm. (2020). Thị trường ví điện tử Việt Nam - cơ hội và thách thức. Tạp Chí Ngân Hàng, 8(10), 1-15.

Mahran, A., \& Enaba, H. (2013). Exploring determinants influencing the intention to use mobile payment service. International Journal of Customer Relationship Marketing and Management, 2(4), 17-37.

Minds, M. f. (2021, Jan 26). Coronavirus: Global GDP to sink by $\$ 22$ trillion over COVID, says $I M F$. https://www.dw.com/en/coronavirusglobal-gdp-to-sink-by-22-trillion-over-covidsays-imf/a-56349323.

Peña-García, N., Gil-Saura, I., RodríguezOrejuela, A., \& Siqueira-Junior, J. R. (2020). Purchase intention and purchase behavior online: A cross-cultural approach. Heliyon, 6(6), 1-11.

Rathore, H. S. (2016). Adoption of digital wallets by consumers. BVIMSR's Journal of Management E-wallets are rapidly gainingacceptance as a mainstream Research, 8(1), 69-76.

Sarika, P., \& Vasantha, S. (2019). Impact of mobile wallets on cashless transaction. International Journal of Recent Technology, 7(6), 1164-1171.

Sharma, S. K., Mangla, S. K., Luthra, S., \& AlSalti, Z. (2018). Mobile wallet inhibitors: Developing a comprehensive theory using an integrated model. Journal of Retailing and Consumer Services, 45(11), 52-63.

Tirtiroglu, E., \& Elbeck, M. (2008). Qualifying purchase intentions using queueing theory. Journal of applied quantitative methods, 3(2), 167-178.

Uddin, M. S., \& Akhi, A. Y. (2014). E-wallet system for Bangladesh an electronic payment system. International Journal of Modeling and Optimization, 4(3), 216-219.

Venkatesh, V., Morris, M. G., Davis, G. B., \& Davis, F. D. (2003). User acceptance of information technology: Toward a unified view. MIS Quarterly, 27(3), 425-478.

Vnexpress. (2020, 11/05). Sụ cạnh tranh trên thi truòng ví điện tư Việt Nam. https://startup.vnexpress.net/tin-tuc/xu- 
huong/su-canh-tranh-tren-thi-truong-vi-dientu-viet-nam-4182358.html.

Vuong, B. N., \& Giao, H. N. K. (2020). The impact of perceived brand globalness on consumers' purchase intention and the moderating role of consumer ethnocentrism: An evidence from Vietnam. Journal of International Consumer Marketing, 32(1), 47-68.

Vuong, B. N., Hieu, V. T., \& Trang, N. T. T. (2020). An empirical analysis of mobile banking adoption in Vietnam. Gestão $e$ Sociedade, 14(1), 3365-3393.

Widyanto, H. A., Kusumawardani, K., \& Septyawanda, A. (2020). Encouraging behavioral intention to use mobile payment: An extension of UTAUT2. Jurnal Muara Ilmu Ekonomi dan Bisnis, 4(1), 87-97.
Wijaya, A., Christin, L., \& Wijaya, W. A. (2020). The antecedents intention of use mobile payment for millennial generation. International Conference on Management, Accounting, and Economy, 151(1), 14-17.

Wulantika, L., \& Zein, S. R. (2020). E-wallet effects on community behavior. Institute of Physics Conference, 879(1), 1-7.

Yang, M., Mamun, A. A., Mohiuddin, M., Nawi, N. C., \& Zainol, N. R. (2021). Cashless transactions: A study on intention and adoption of e-wallets. Sustainability, 13(2), 1-18.

Zhao, W., \& Othman, M. N. (2010). Predicting and explaining complaint intention and behavior of malaysian consumers: An application of the planned behavior theory. Advances in International Marketing, 9(1), 229-252. 